\title{
Microstrip Patch Antenna Assisted Compact Dual Band Planar Crossover
}

\author{
Sreedevi K. Menon \\ Department of Electronics and Communication Engineering, Amrita University, Amritapuri 690525, India; \\ sreedevikmenon@am.amrita.edu
}

Received: 13 September 2017; Accepted: 28 September 2017; Published: 30 September 2017

\begin{abstract}
In Microwave Monolithic Integrated Circuits, crossovers maintain signal purity when transmission lines overlap with each other. A simple crossover for dual band applications, particularly suitable for the development of smart antennas, is presented in this paper. Derived from conventional patch antenna, the proposed crossovers are easy to design and fabricate, thus reducing the overall complexity. Design is verified for a dual band crossover at 2.4/5.23 GHz on FR4 (Fiberglass Reinforced) epoxy and tested using Keysight E5080 A Vector Network Analyser. The results obtained by simulation and measurement are in agreement. The proposed crossovers find application in a Butler matrix for phased array and smart antenna systems.
\end{abstract}

Keywords: butler matrix; crossover; reconfigurable patch; microstrip patch; dual band

\section{Introduction}

Microstrip patch antennas continue to gather attention for communication systems, due to their affordability, compactness, light weight, and simple methods of fabrication [1]. Patch antennas provide dual-frequency operation, feed line flexibility and frequency agility. They can be modified for beam scanning omnidirectional patterning, dual and circular polarizations and broad bandwidth [1]. These characteristics are particularly suitable for the design of reconfigurable antennas. Patch antennas has been reconfigured for frequency [2], radiation pattern [3] and so on. Different methods to analyse the performance of this class of antennas are also available in the literature [1-4].

In this work a reconfigured microstrip patch antenna for crossover applications is proposed. Crossovers are used to avoid signal interference at the intersection of two transmission lines, usually in phased arrays and smart antennas. The high capacity in wireless networks employing smart antenna systems is accomplished by orienting the radiation in the desired direction. Smart antennas employ an array of antennas for radiation and can be deployed as a switched beam system or an adaptive array system [5]. In this, the switched beam antenna can be realized easily at low cost in comparison with an adaptive antenna array. A switched beam antenna requires radiating elements, a beamforming network and Radio Frequency (RF) switches [6] while adaptive array systems are much more complex, requiring advanced signal processing [7] techniques. Butler matrix is one of the common method used in switched beam system has $90^{\circ}$ hybrid coupler, delay lines and crossover associated with it [8].

Generally available crossovers can be classified into three different types. In the first type, the signal path is provided as an air-bridge [9] or bond wires [10]. Air wedge is realized using microelectromechanical systems (MEMS) processing and bond wires, increasing the cost and complexity of fabrication. The second kind adopts the multilayer configuration, where the signals are transmitted between different layers by microstrip-coplanar waveguide-microstrip transitions [11,12] and microstrip-slotline-microstrip transitions. Since double side alignment is required for these crossovers they become more complex and it is also inconvenient to integrate them with other circuits and components. The third kind is the recently introduced planar crossover. Cascaded two section 
branchline couplers were first introduced as planar crossovers providing an isolation of about $20 \mathrm{~dB}$ [13]. There after, many planar crossovers were introduced, including multi-section cascaded branchline structure [14] and double ring structures [15]. A compact planar crossover using quarter wavelength lines providing wide bandwidth is reported in [16]. A multimode cross-shaped resonator can perform as both crossover and filter [17]. By the inclusion of defected ground structures, a multi-layered compact crossover is realized using coupled lines in [18].

The aforementioned crossovers operate at single frequency only. In the case of multi band operation, passive components required for transceiver systems should be cost effective and compact with performance at multiple frequencies. A dual band crossover was designed with three section branchline structures by extending the single band crossovers [19]. Stub-loaded branchline couplers are also found to have good performance as crossovers [20]. These crossovers were designed for only small-frequency ratio applications and provide less isolation. Henin etal., introduced the use of patch antenna as planar crossovers [21]. Many modifications of this have been reported [22,23] which confirms the utilization of patch antenna as planar crossover. This paper extends the concept of patch as crossover to have dual band characteristics. The Diamond Patch Crossover (DPC) analysed here works at $2.4 \mathrm{GHz}$ and $5.23 \mathrm{GHz}$. A comparative study of other patch based crossover with the dual band one is also presented.

\section{Crossover}

Intersection of transmission lines in a circuit leads to reduced signal-to-noise ratio (SNR). A 'crossover' at the intersection addresses this effectively. As presented in Figure 1, the crossover has decoupled adjacent ports with power maintained between opposite ports.

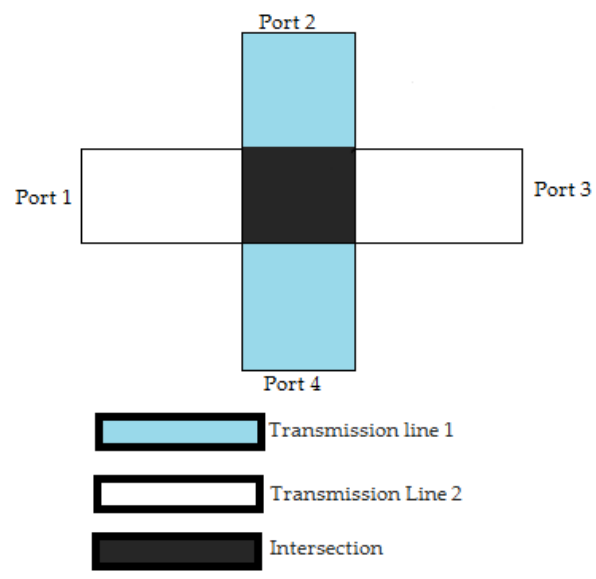

Figure 1. Crossover.

Assuming reciprocal, lossless and matched conditions and neglecting phase variations; with perfect isolation between adjacent ports the ideal $S$ matrix for the crossover in Figure 1 will be,

$$
[S]=\left[\begin{array}{llll}
0 & 0 & 1 & 0 \\
0 & 0 & 0 & 1 \\
1 & 0 & 0 & 0 \\
0 & 1 & 0 & 0
\end{array}\right]
$$

Due to the overlap in a practical circuit, the transmission coefficient will not be 1 due to attenuation and isolation will not be zero. So for designing any crossover, the isolation should be maximized and insertion loss (attenuation) should be minimum maintaining compactness. In this paper, the intersection is realized as patch with feed location exciting perpendicular polarization for adjacent ports and parallel polarizations for opposite ports. This ensures the signal flow is maintained 
between the opposite ports while the adjacent ports are decoupled. The design and detailed study are presented in the next section.

\section{Microstrip Patch Reconfigured as Planar Crossover}

For initial analysis, a circular patch is modified as crossover as shown in Figure 2. The patch is energized at four locations using $50 \Omega$ microstrip lines, making adjacent ports to have orthogonal polarization.

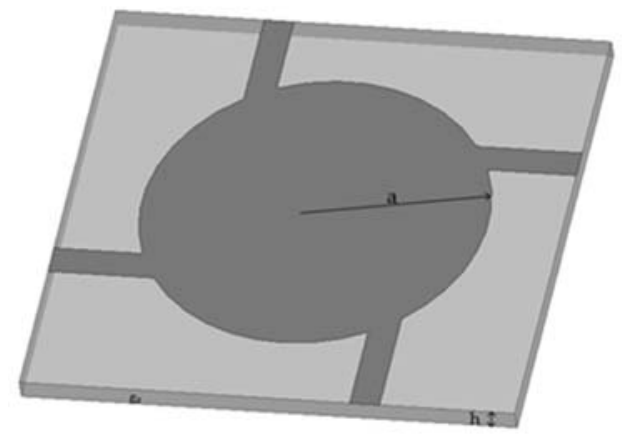

(a)

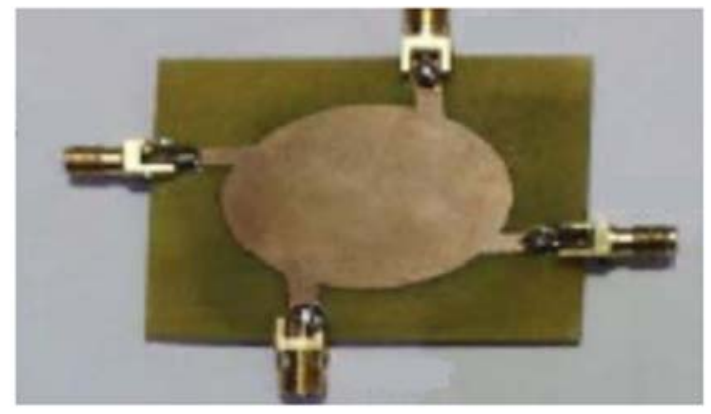

(b)

Figure 2. Circular Patch Crossover(CPC). (a) Schematic of CPC; (b) Photo of the fabricated prototype.

This crossover provides single band operation with $\sim 15 \mathrm{~dB}$ isolation between the adjacent ports and the performance is plotted in Figure 3. Eventhough return loss of $20 \mathrm{~dB}$ is observed at $5.2 \mathrm{GHz}$ the transmission and isolation are very poor, thus not performing as crossover at that frequency.

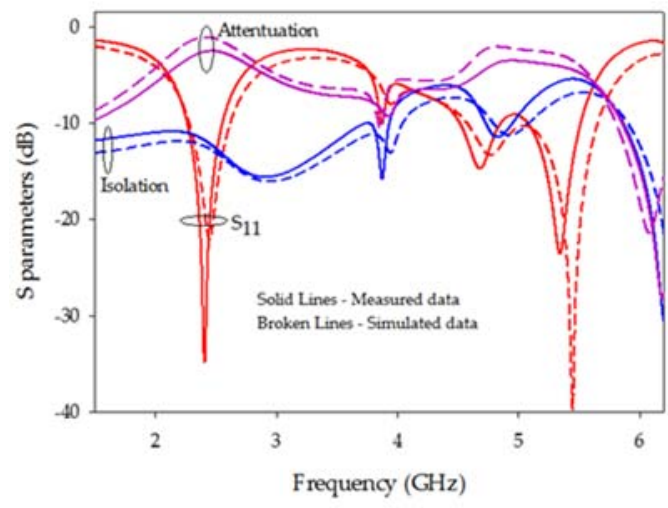

(a)

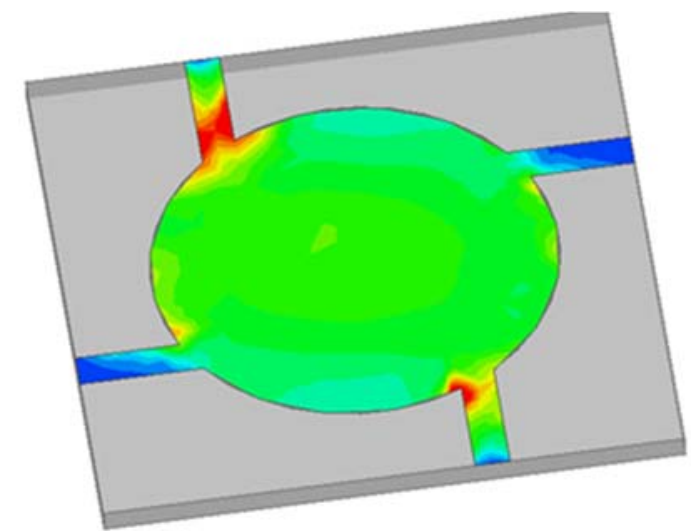

(b)

Figure 3. (a) Variation of S parameters with frequency for a CPC; (b) Current distribution of CPC at $2.45 \mathrm{GHz}$.

To enable the microstrip patch assisted crossover to have dual band characteristics, the intersection of transmission lines is modified as square and diamond patches. The observations are presented in detail in the next section. 


\section{Microstrip Patch Reconfigured as Dual Band Planar Crossover}

\subsection{Square Patch Crossover (SPC)}

A square patch crossover (SPC) is realized by replacing the transmission line intersection with half-wavelength square patch excited with two sets of perpendicular feed lines as demonstrated in Figure 4.

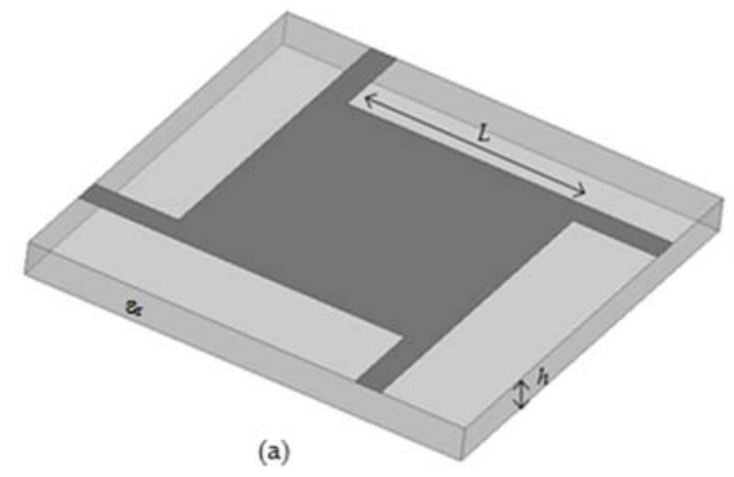

(a)

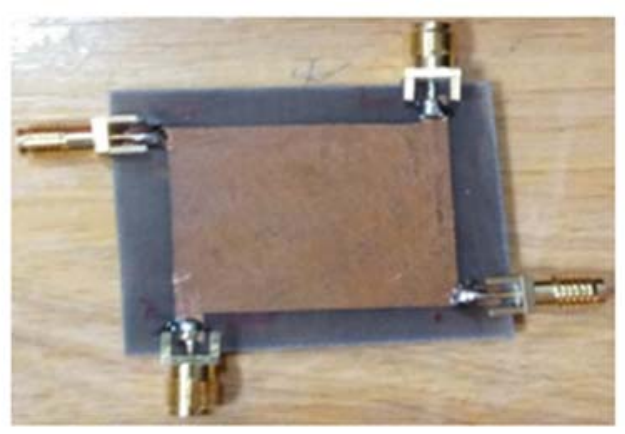

(b)

Figure 4. Square Patch Crossover (SPC). (a) Schematic of SPC; (b) Photo of the fabricated prototype.

To ensure isolation between adjacent ports, the orthogonal feed lines are provided at the corners of the patch which energizes the Transverse Magnetic (TM) modes $\mathrm{TM}_{010}$ and $\mathrm{TM}_{100}$ modes. Considering cavity model [1] for the patch, the magnetic field distribution for $\mathrm{TM}_{100}$ mode is

$$
H_{y}=A_{1} \sin \frac{\pi x}{L}, H_{x}=0
$$

and for $\mathrm{TM}_{010}$ mode field is:

$$
H_{x}=A_{2} \sin \frac{\pi y}{L}, H_{y}=0
$$

where $A_{1}$ and $A_{2}$ are the fields amplitude and $L$ is the patch length. The operating frequency $f_{r}$ is given as:

$$
f_{r}=\frac{C}{2 L \sqrt{\varepsilon_{r}}}
$$

Since the mode is TM, $E_{z}$ is present and the two fundamental modes have perpendicular magnetic fields. The Poyting Vector $(S)$ is perpendicular to electric and magnetic fields.

$$
\bar{S}=\bar{E} \times \bar{H}
$$

For $\mathrm{TM}_{100}$ mode,

$$
\overline{S_{x}}=\overline{E_{z}} \times \overline{H_{y}}
$$

For $\mathrm{TM}_{010}$ mode,

$$
\overline{S_{y}}=\overline{E_{z}} \times \overline{H_{x}}
$$

So the power flow for the $\mathrm{TM}_{100}$ mode and for the $\mathrm{TM}_{010}$ mode is in perpendicular directions ( $x$-direction and $y$-direction respectively). So the opposite ports (port 1 and 3 and port 2 and 4 ) get properly aligned to couple energy from the same modes. The adjacent ports become decoupled by orthogonal modes. Thus proper isolation (between the adjacent ports) and low insertion loss (between the opposite ports) is maintained among the concerned ports.

Designed using Equation (3), on the dielectric substrate FR4 epoxy $\left(\varepsilon_{r}=4.4, h=1.6 \mathrm{~mm}\right.$, $\tan \delta=0.018)$ a square patch is simulated using ANSYS HFSS (14, ANSYS Inc., Pittsburgh, PA, USA) 
and fabricated to have crossover characteristics at $2.4 \mathrm{GHz}$. The feed lines are designed for $50 \Omega$. The reflection and transmission characteristics of SPC are plotted and shown in Figure 5.

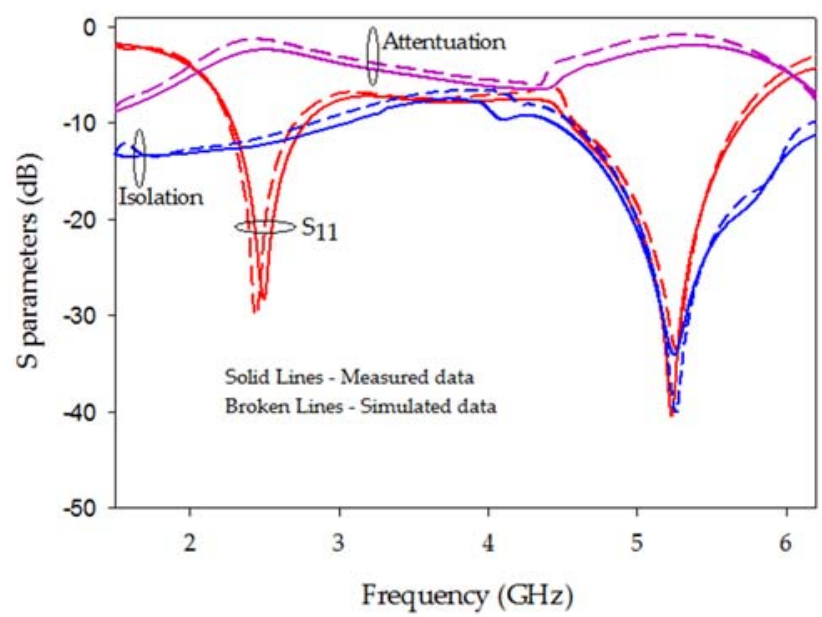

Figure 5. Variation of S parameters with frequency for a Square Patch Crossover.

The edge feed energizes the next degenerate modes $\left(\mathrm{TM}_{020}\right.$ and $\left.\mathrm{TM}_{200}\right)$, having resonance at $5.2 \mathrm{GHz}$, thus providing a dual band response. The current distribution obtained confirms the use of the square patch as effective crossover and is presented in Figure 6. It can be seen that diagonally opposite ports show the same polarization, thus allowing signal flow between them for both the frequencies.

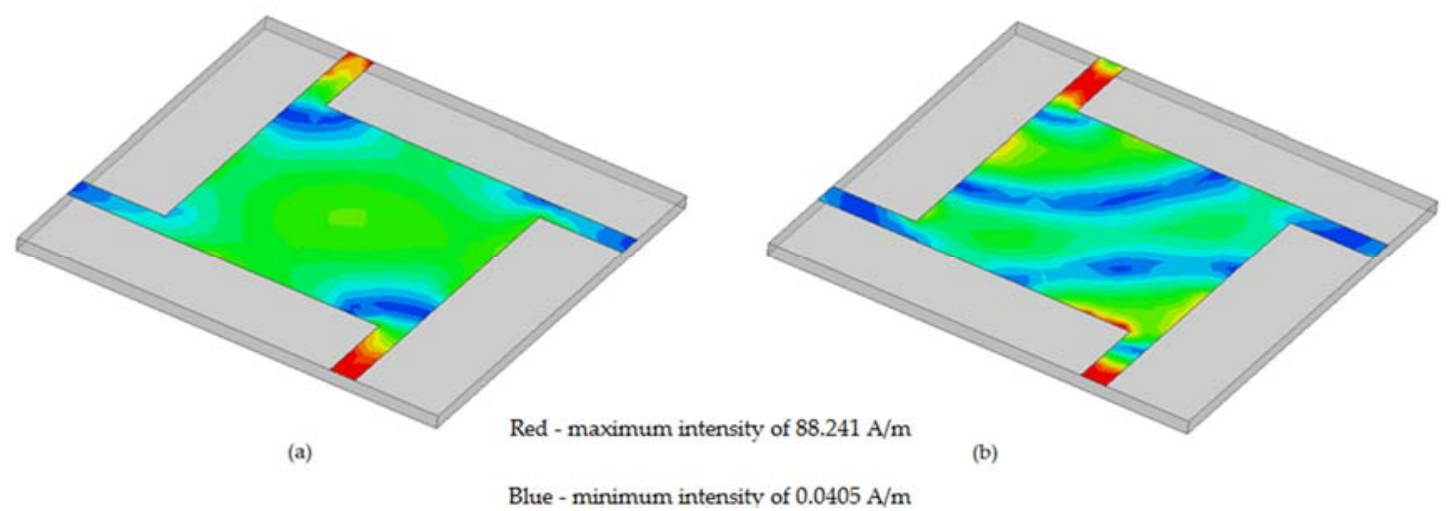

Figure 6. Current distribution of Square Patch Crossover: (a) at $2.43 \mathrm{GHz}$; (b) at $5.2 \mathrm{GHz}$.

\subsection{Diamond Patch Crossover (DPC)}

A diamond patch crossover (DPC) is designed by changing the excitation of SPC as demonstrated in Figure 7.

The scattering parameters observed for the DPC is as presented in Figure 8. The current distribution at both the frequencies ascertain the performance as crossover and is as shown in Figure 9.

For DPC the area needed for designing the dual band crossover is $27 \%$ less than that of the SPC. The characteristics observed for the crossovers are consolidated in Table 1.

The simulated and experimental results obtained establish the use of microstrip patch antennas with proper feed location as a potential candidate as crossover. 


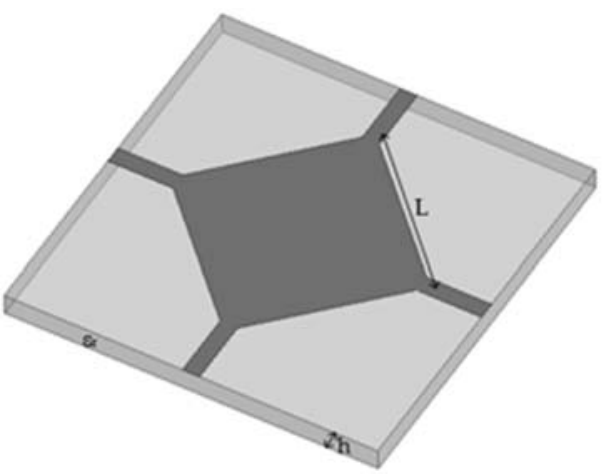

(a)

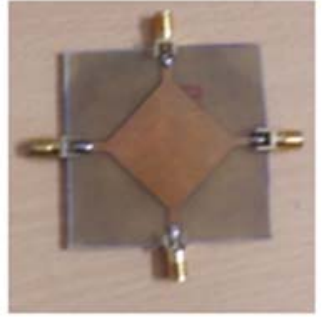

(b)

Figure 7. Diamond Patch Crossover (DPC). (a) Schematic of DPC; (b) Photo of the fabricated prototype.

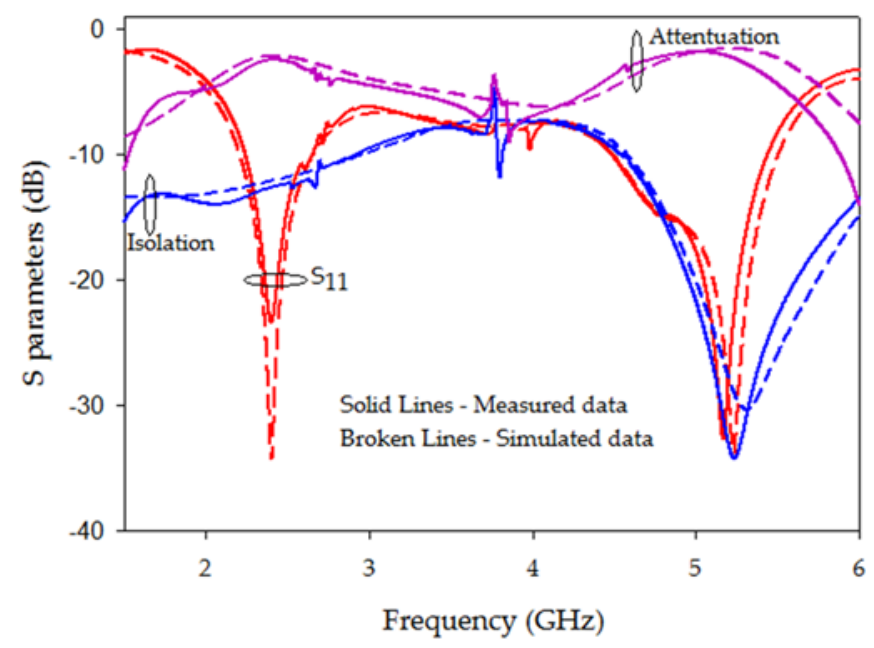

Figure 8. Variation of $S$ parameters with frequency for DPC.

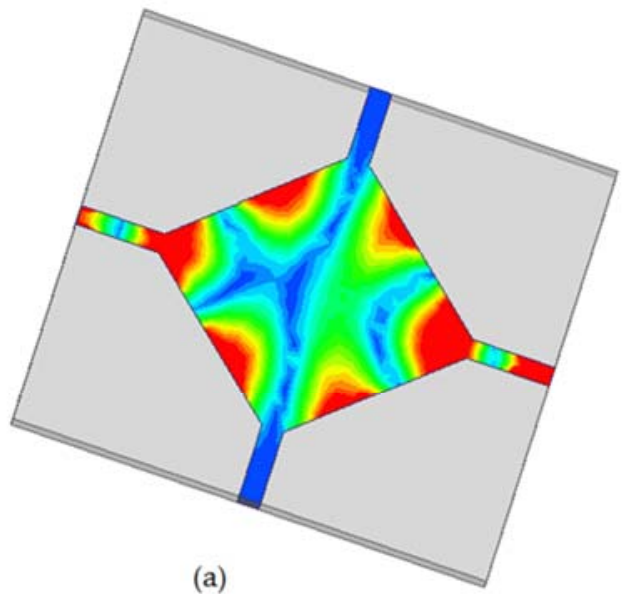

Red - maximum intensity of $88.241 \mathrm{~A} / \mathrm{m}$

Blue - minimum intensity of $0.0405 \mathrm{~A} / \mathrm{m}$

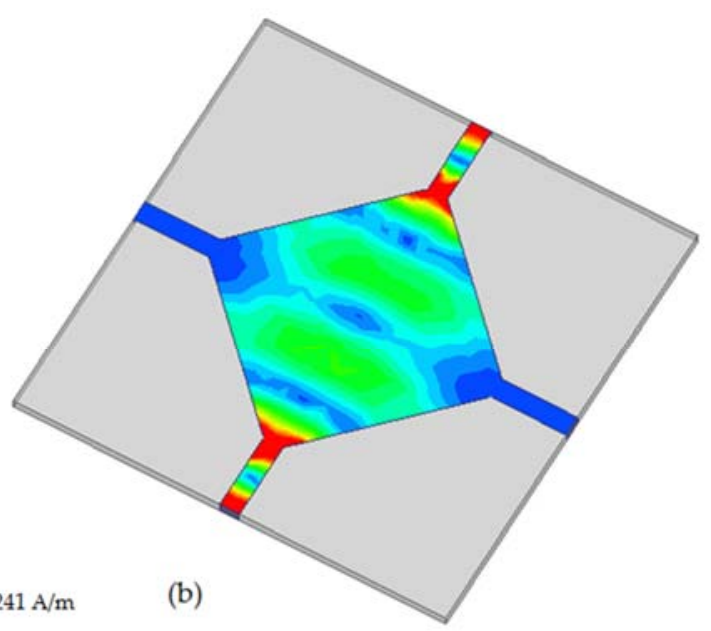

(b)

Figure 9. Current distribution of Diamond Patch Crossover; (a) at $2.43 \mathrm{GHz}$; (b) at $5.2 \mathrm{GHz}$. 
Table 1. Comparison of Dual band Crossover characteristics - Experimental data $\left(\varepsilon_{r}=4.4, h=1.6 \mathrm{~mm}\right.$, $\tan \delta=0.018)$. SPC: Square patch crossover; DPC: Diamond patch crossover.

\begin{tabular}{cccccc}
\hline Type of Crossover & $\begin{array}{c}\text { Frequency of } \\
\text { Operation }(\mathbf{G H z})\end{array}$ & $\begin{array}{c}\text { Return Loss } \\
\mathbf{( d B}\end{array}$ & $\begin{array}{c}\text { Insertion Loss } \\
(\mathbf{d B})\end{array}$ & $\begin{array}{c}\text { Isolation } \\
(\mathbf{d B})\end{array}$ & Area $\left(\mathbf{m m}^{\mathbf{2}}\right)$ \\
\hline \multirow{2}{*}{ SPC } & 2.43 & 28 & 1 & 12 & 930.25 \\
& 5.2 & 40 & 1.2 & 33 & - \\
DPC & 2.43 & 23 & 2 & 12 & 676 \\
\end{tabular}

\section{Discussion}

The performance of the proposed crossover compared to the others to which this paper has referred is presented in Table 2. The reduction in isolation for the first band is due to the high loss tangent of FR4 which could be appreciably improved on using low loss substrates.

Table 2. Comparison of Crossovers.

\begin{tabular}{cccccc}
\hline \multirow{2}{*}{ Type of Crossover } & \multicolumn{2}{c}{ Substrate Characteristics } & Performance & Isolation(dB) & Size $\left(\lambda_{g} \times \lambda_{g}\right)$ \\
\cline { 2 - 3 } & $\varepsilon_{r}$ & $\tan \delta$ & & & \\
\hline Ref [16] & 10.2 & 0.0035 & Single band & $<20$ & $0.25 \times 0.25$ \\
Ref [17] & 3.38 & 0.0027 & Single band & $<20$ & $0.24 \times 0.33$ \\
Ref [18] & 2.65 & 0.003 & Single band & $<20$ & $0.45 \times 0.28$ \\
Ref [19] & 2.2 & 0.0009 & Dual band & $>10 />10$ & $0.58 \times 0.58$ \\
Ref [20] & 3.55 & 0.0027 & Dual band & $>25 />25$ & $1.00 \times 0.78$ \\
Ref [21] & 10.2 & 0.0035 & Single band & $<17$ & $0.63 \times 0.63$ \\
SPC & 4.4 & 0.018 & Dual band & $>12 />33$ & $0.50 \times 0.50$ \\
DPC & 4.4 & 0.018 & Dual band & $>12 />34$ & $0.42 \times 0.42$ \\
\hline
\end{tabular}

\section{Conclusions}

In this paper a new microstrip patch antenna assisted planar dual frequency crossover for maintaining signal purity at transmission line intersections is presented. From Table 2, it can be inferred that the proposed crossover is compact compared to the other microstrip counter parts, provides dual frequency operation and is potentially suitable in designing phased array and smart antenna systems.

Conflicts of Interest: The authors declare no conflict of interest.

\section{References}

1. Constantine, A. Balanis: Antenna Theory and Design, 3rd ed.; John Wileys \& Sons, Inc.: Hoboken, NJ, USA, 2005.

2. Majid, H.A.; Rahim, M.K.A.; Hamid, M.; Murad, N.A.; Ismail, M.F. Frequency-Reconfigurable Microstrip Patch-Slot Antenna. IEEE Antennas Wirel. Propag. Lett. 2013, 12, 218-220. [CrossRef]

3. Lu, Z.; Yang, X.; Tan, G. A Multidirectional Pattern-Reconfigurable Patch Antenna With CSRR on the Ground. IEEE Antennas Wirel. Propag. Lett. 2017, 16, 416-419. [CrossRef]

4. Santhosh, S.; Arunselvan, S.J.; Aazam, S.H.; Gandhiraj, R.; Soman, K.P. Performance analysis of microstrip antenna using GNU radio with USRP N210. Smart Innov. Syst. Technol. 2015, 33, 239-249.

5. Fernandes, M.; Bhandare, A.; Dessai, C.; Virani, H. A Wideband Switched Beam Patch Antenna Array for LTE and Wi-Fi. In Proceedings of the 2013 Annual IEEE India Conference (INDICON), Mumbai, India, 13-15 December 2013; pp. 1-6.

6. Anderson, S.; Millnert, M.; Viberg, M.; Wahlberg, B. An adaptive array for mobile communication systems. IEEE Trans. Veh. Technol. 1991, 40, 230-236. [CrossRef] 
7. Ibrahim, S.Z.; Rahim, M.K.A. Switched Beam Antenna using Omnidirectional Antenna Array. In Proceedings of the Asia-Pacific Conference on Applied Electromagnetics, Melaka, Malaysia, 4-6 December 2007; pp. 1-4.

8. Bhowmik, W.; Srivastava, S. Optimum Design of a $4 \times 4$ Planar Butler Matrix Array for WLAN Application. J. Telecommun. 2010, 2, 68-74.

9. Young-Min, J. Broad Band Patch Antennas Using a Wedge-Shaped Air Dielectric Substrate. IEEE Antennas Propag. Soc. Int. Symp. 1999, 2, 932-935.

10. Goossen, K.W. On the Design of Coplanar Bond Wires as Transmission Lines. IEEE Microw. Guided Wave Lett. 1999, 9, 798-799. [CrossRef]

11. Liu, W.; Zhang, Z.; Feng, Z.; Iskander, M.F. A compact wideband microstrip crossover. IEEE Microw. Wirel. Compon. Lett. 2012, 22, 254-256. [CrossRef]

12. Abbosh, A.; Ibrahim, S.; Karim, M. Ultra-wideband crossover using microstrip-to-coplanar waveguide transitions. IEEE Microw. Wirel. Compon. Lett. 2012, 22, 500-502. [CrossRef]

13. Wight, J.S.; Chudobiak, W.J.; Makios, V. A microstrip and stripline crossover structure. IEEE Trans. Microw. Theory Tech. 1976, 24, 270. [CrossRef]

14. Lin, F.; Chu, Q.X.; Wong, S.W. Dual band planar crossover with two section branch line structure. IEEE Trans. Microw. Theory Tech. 2013, 61, 2309-2316. [CrossRef]

15. Tang, C.; Chuang, W. Design of the Planar Six-Port Crossover With Double Rings. IEEE Microw. Wirel. Compon. Lett. 2015, 25, 651-653. [CrossRef]

16. Xin, N.L.; Cuiping, Y.; Yuanan, L.; Shulan, L.; Fan, W.; Ming, S. A Novel Compact Planar Crossover with Simple Design Procedure. In Proceedings of the Asia-Pacific Microwave Conference, Yokohama, Japan, 7-10 December 2010; pp. 1633-1636.

17. Guo, Q.Y.; Zhang, X.Y.; Gao, L. Novel Compact Planar Crossover With Bandpass Response Based on Cross-Shaped Resonator. IEEE Trans. Compon. Packag. Manuf. Technol. 2017, PP, 1-9. [CrossRef]

18. Feng, W.; Zhang, T.; Che, W. Compact Single-band Planar Crossover Based on Coupled Lines. In Proceedings of the 46th European Microwave Conference, London, UK, 4-6 October 2016.

19. Lee, Z.-W.; Pang, Y.-H. Compact planar dual-band crossover using two-section branch-line coupler. Electron. Lett. 2012, 48, 1348-1349. [CrossRef]

20. Shao, J.; Ren, H.; Arigong, B.; Li, C.; Zhang, H. A fully symmetrical crossover and its dual-frequency application. IEEE Trans. Microw. Theory Tech. 2012, 60, 2410-2416. [CrossRef]

21. Henin, B.; Abbosh, A. Design of compact planar crossover using Sierpinski carpet microstrip patch. IET Microw. Antennas Propag. 2015, 7, 54-60. [CrossRef]

22. Jayakrishnan, V.M.; Menon, S.K. Circular Patch Antenna Based Planar Crossover. In Proceedings of the 3rd International Conference on Signal Processing and Integrated Networks, Noida, India, 11-12 February 2016; pp. 250-254.

23. Purnima, G.; Menon, S.K. Microstrip patch based high isolation planar crossover for beamforming applications. In Proceedings of the IEEE International WIE Conference on Electrical and Computer Engineering (WIECON-ECE), Pune, India, 19-21 December 2016; pp. 184-187.

(C) 2017 by the author. Licensee MDPI, Basel, Switzerland. This article is an open access article distributed under the terms and conditions of the Creative Commons Attribution (CC BY) license (http:// creativecommons.org/licenses/by/4.0/). 